\title{
Importance of Diet Quality and Healthy Lifestyle Assessment
}

\author{
Ceren Gezer* \\ Department of Nutrition and Dietetics, Eastern Mediterranean University, Cyprus
}

*Corresponding author:Ceren Gezer, Department of Nutrition and Dietetics, Faculty of Health Sciences, Estern Mediterranean University, Famagusta, North Cyprus/Mersin 10, Turkey

Submission: 睯 March 10, 2018; Published: 眥 March 20, 2018

\section{Editorial}

Healthy lifestyle can be defined as controlling all behaviours affecting the health of the individual, managing daily activities to improve health and reducing disease risks. Lifestyle behaviours affect disease risk and life quality. The development of healthy lifestyle behaviours, especially nutrition and physical activity is associated with type 2 diabetes, cardio-metabolic diseases and cancer risks. World Health Organization defines life quality as "individual's perception of their position in life in the context of the culture and value systems in which they live and in relation to their goals, expectations, standards and concerns". Therefore, healthy lifestyle behaviours, especially nutrition and physical activity are related to life quality. Measuring the risk of chronic disease associated with diet quality, healthy lifestyle and life quality is very important in terms of improving public health [1-3].

Various methods and techniques are used to evaluate nutritional habits and nutritional consumption status. While traditional epidemiological nutrition techniques (24-hour retrospective food consumption, food frequency, etc.) allow the determination of the effect of a particular food and nutrient item, diet quality which primarily represents energy and nutrient sufficiency is a good method for determining diet. Diet quality is an important parameter in order to determine changes in nutritional status of both developed and developing countries and to develop nutritional policies improving public health. There are various scales developed to assess diet quality. The main ones were Healthy Eating Index, Diet Quality Index, Mediterranean Diet Compliance, and Mediterranean Diet Score. There are also various scales developed to assess life quality. The most frequently used ones are Quality of Life Index Short Form-36 and World Health Organization Quality of Life. There are also non-invasive scales based on anthropometric measurements and basic nutrition habits for disease risk assessment. The Finnish Diabetes Risk Score is a good example of such scales. All of these scales can be effective to determine the relationship between chronic disease risk, diet quality and life quality with nutritional epidemiology studies and improving public health policies. In addition to epidemiological studies, experimental studies/clinical trials can be used to assess the relation between treatment efficacy disease course and, diet quality and life quality. The application of these scales by face to face interview method is very important in the maintenance of accurate data collection. Furthermore, in recent years when nutritional genomics research has become increasingly important; exploiting these scales can be effective in revealing the relationship between diet quality and genetics [4-9].

To conclude, healthy lifestyle behaviors, scales for assessing diet quality and life quality continue to shed light on the future of public health by linking genomes with the prevention of disease risks and the effectiveness of disease treatments.

\section{References}

1. den Braver NR, de Vet E, Duijzer G, Ter Beek J, Jansen SC, et al. (2017) Determinants of lifestyle behaviour change to prevent type 2 diabetes in high-risk individuals. Int J Behav Nutr Phys Act 14(1): 78-88.

2. Guerrero MLP, Rodríguez P (2017) Diet quality indices for nutrition assessment: Types and applications. In: Hueda MC (Ed.), Functional Food - Improve Health through Adequate Food. Intech, UK.

3. World Health Organization (1996) WHOQOL-BREF introduction, administration, scoring and generic version of the assessment. Geneva: World Health Organization

4. Heyward VH, Wagner RR (2004) Applied body composition assesment. Human Kinetics.

5. Kim S, Haines PS, Siega-Riz AM, Popkin BM (2003) The Diet Quality Index-International (DQI-I) provides an effective tool for cross-national comparison of diet quality as illustrated by China and the United States. J Nutr 133(11): 3476-3484.

6. Kim S, Popkin BM, Siega-Riz AM, Haines P, Arab L (2004) A cross-national comparison of lifestyle between China and the United States, using a comprehensive cross-national measurment tool of healthfulness of lifestyles: the Lifestyle Index. Prev Med 38(2): 160-171.

7. Lindström J, Tuomilehto J (2003) The diabetes risk score. Diabetes Care 26(3): 725-731.

8. McHorney CA, Ware JE, Lu JFR, Sherbourne CD (1994) The MOS 36-item short-form health survey (SF-36®): III. Tests of data quality, scaling assumptions and reliability across diverse patient groups. Med Care 32(1): 40-66.

9. Tucker KL, Smith CE, Lai CQ Ordovas JM (2013) Quantifying diet for nutrigenomic studies. Annu Rev Nutr 33: 349-371. 
(c) (i) Creative Commons Attribution 4.0

For possible submissions Click Here

Submit Article
RISM Inmitis

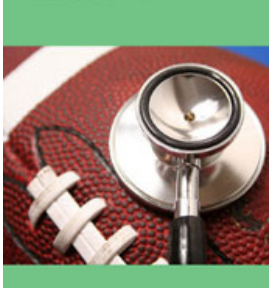

Research \& Investigations in Sports Medicine

\section{Benefits of Publishing with us}

- High-level peer review and editorial services

- Freely accessible online immediately upon publication

- Authors retain the copyright to their work

- Licensing it under a Creative Commons license

- Visibility through different online platforms 